\title{
Application of Online Learning and Classroom Teaching
}

\author{
Bing Ruan ${ }^{1, a *}$ and Minjun Yang ${ }^{2, b}$ \\ ${ }^{1}$ Mathematics and Computer Science, Wuhan Polytechnic University, China \\ ${ }^{2}$ Mathematics and Computer Science, Wuhan Polytechnic University, China \\ aruan504@126.com, ${ }^{\text {b7}} 763892948 @ q q . c o m$
}

\begin{abstract}
Keywords: Online Learning; Classroom Teaching; Blended; Self-pace; Need for Learning
\end{abstract}
\begin{abstract}
The blended model based on online learning and classroom teaching is to break through the traditional education, tring to establish the student-centered learning model. In the model, it no longer relies on the traditional teaching method which takes the teacher's teaching as the main body, but it takes the students themselves as the main body. The aim of online learning and classroom teaching is to give the students choices to choose the study's content, method and schedule. It also aims to let students active in the learning process, train students to have thinking ability and the exploration spirit, meet the need of students' personalized learning, enhance students' motivation in learning. Finally, let students achieve their learning effects maximum.
\end{abstract}

\section{Introduction}

Traditional factory education model is teacher-centered. In the model, teachers rule the classroom teaching and the study pace of the learners excessively, so that sometimes they ignore the students' feelings. This model makes the students feel lack of the sense of participation, as a result, the students could not show their learning independence well. When the knowledge becomes networked, In the class, it is not the smartest one who stands in front of the classroom teaching us[1]. The basic character of the future education is that let students themselves as the main body and become the master of learning. In the final analysis, the learning process should rely on the learners themselves to lead and complete. Nowadays, the past model of teacher-centered is transformed to the new model of student-centered learning. The role of the teacher is a companion, instructor and study partner. They take active participation as the member in the learning process to help and lead the construction of the model of student-centered learning.

It has many advantages to carry out the reform of the blended learning model based on online platform and physical classroom. On the one hand, it helps the traditional class play its traditional function. On the other hand, it hopes to change the traditional class condition which overvalued knowledge instruction but ignored the student's learning status. Through the study activity which lead by the teachers' online teaching and classroom teaching, it gradually improves students' study will and impetus. So that students could achieve the study of self-control. The study model could change students from passive learning to active learning. The reform will achieve the students' autonomous development. The process of acquiring the basic knowledge and basic skills, in the meanwhile, will becomes the process of learning how to study and form the correct values.

\section{Application of Online Learning and Classroom Teaching}

Different students will have different initial level and background knowledge, so it is not appropriate for the teacher to adopt the consistent progress and uniform standard. Computer Programmingcourse in order to satisfy the need of different level of students' study and further improve the quality of teaching, so it combines classroom teaching and online teaching organically[2, 3]. In order to adapt to the unique need of every students', the application of class have five process: teaching design, classroom teaching, self-study after class, class discussion and course assessment. The whole learning process data is collected by the online platform. How to guide students to learn class according to the teaching design and not to increase the revolution 
burden to the teachers? The key of solving this problem is the application of online learning and classroom teaching. Fig. 1 the illustration of the effective fusion of online learning and classroom teaching by mind map.

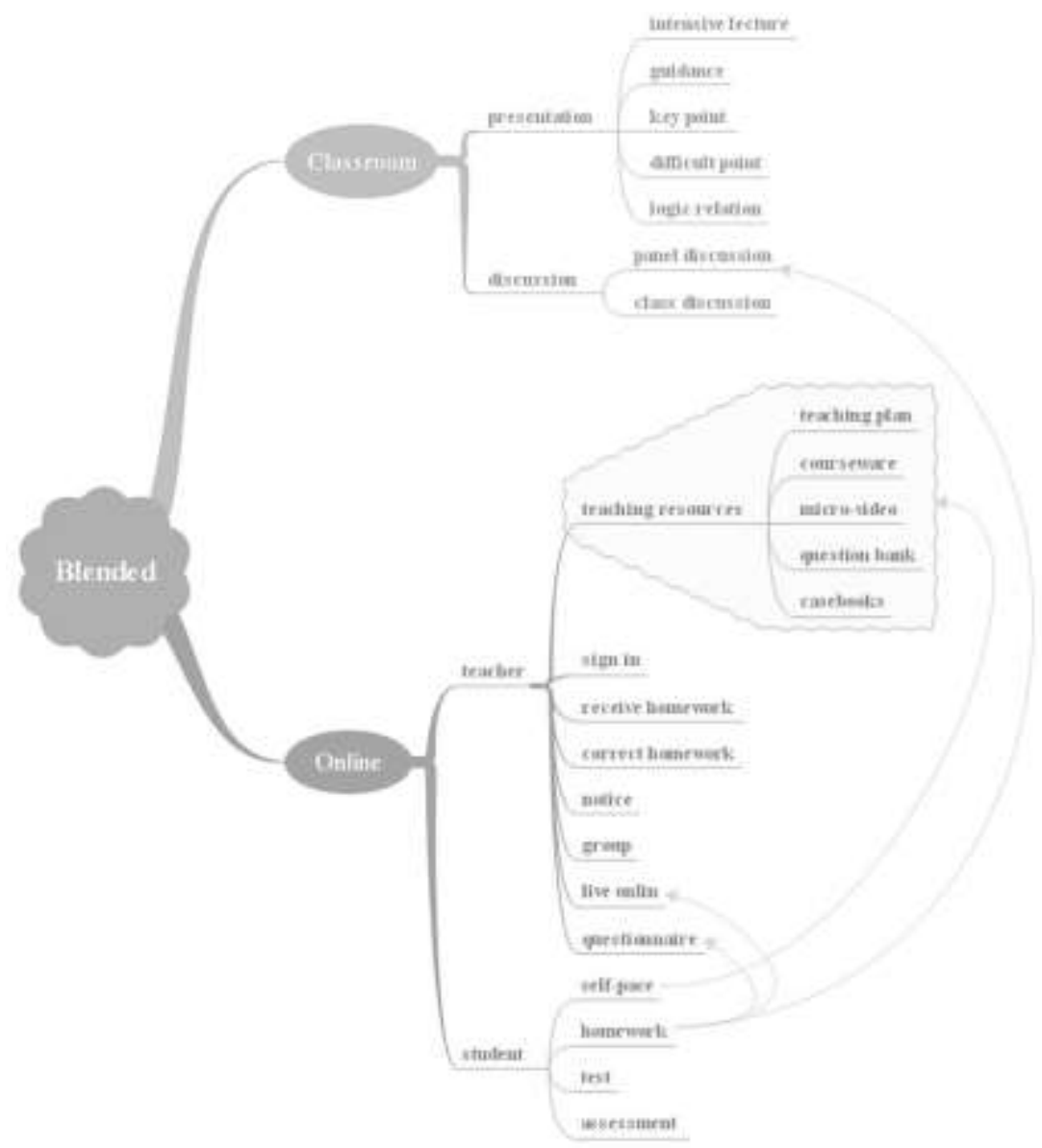

Figure 1. The effective fusion of online learning and classroom teaching

Teaching Design. Teaching design include design the development of online platform and teaching activity two parts. Computer Programming online teaching platform has started to design and develop since 2015. The construction of course requests education resource could help students gradually understand the concept of programming design concepts. It also hopes students could internalize and absorb from future self-paced. Our university online teaching serve platform not only offer abundant teaching resource, but also equipped with the basic public service of course assessment and learning of evaluation. The platform adopt advanced process scoring, synchronize the PC terminal and APP terminal. Whatever inside and outside the classroom, it is convenient for both teachers and students 's teaching interaction[4].

Teaching activity, the core of teaching design, is started at the beginning of class. According to the professional characteristics of the students, the teachers need to prepare corresponding syllabus and teaching implementation plan. Teachers should consider the relation between the past teaching with the student's knowledge and they need to divide the range of teaching, analyze perspective, examples and so on. They also need to prepare video courseware, teaching material, study resource for students. Teachers could use online platform for the whole teaching regulation, such as sign in for class, send and receive assignments, grade assignments, release notices, test exams, discussion groups and so on.

Classroom Teaching. Teacher try their best to improve the teaching quality, but some of students lack of study motivation. Not being serious and distracted in class both the challenges that teachers face with now. To improve students' study motivation and let them like to study on their own, teachers should break through the traditional factory model, improve class learning model, and adopt the study style that makes the students as the main body. According to the theory of Malcolm 
S. Knowles[5], the character of teacher has been translated, they become the leader and helper of the students' study. Teacher teach students from the relatively macro perspective of the framework teaching. They tell students the study's request, goal and aim and explain the important and difficult points in learning. Teacher lead students' self-paced study by teaching them the content and relationship between the chapters. In addition, the micro-video offered on online platform undertake a part of "teaching work". This makes the teaching more flexibility and makes the teacher could put enough time and energy into the face to face study interaction with students. The class no longer is the infuse knowledge transfer, and the students no longer is the passive learners in the class. To some degree, this type of class solve the problems that the teaching efficiency is low and the content is not humanized and so on.

Self-study after Class. There are the study ability difference between the students, some absorb knowledge quickly, some absorb knowledge slow. The key of achieving the same level of mastering knowledge of students is self-paced study. The micro-video which is offered on online platform is focused on the teaching content's key points. As the supplement of the class teaching, it could offer powerful help for students' self-study. The computer technology and internet technology make the learning of class more flexible. Students could get hold of the rate of progress independently[2][3]. According to the students' learning situation, they could study at any time and in any place, so they could study what they don't understand by watching the micro-video repeatedly. In the meanwhile, the online platform also offer the question bank for students to test. The test result could offer the students' study behavior. These feedback information not only make students acquire the sense of achievement, but also let them know what remains to be done. The study type of self-study let students absorb knowledge more active.

The statistical system of online platform track every student's study process, and feedback the learning condition to the teacher. Teacher could know every students' learning condition and problem record clearly, such as the condition that what tasks have the students completed, what is the accuracy of the practice test, and how long dost it take to answer the question. From the statistical system of online platform, teacher could know what knowledge points video is played over and over again, which problems are more likely to go wrong. Even the time when students prefer to $\log$ on to the platform to complete self-study the teacher also could know. Referring to the feedback data and analyze results, teacher could release notices and instruct students more targeted, they could give full play to the role of a teacher as a mentor.

Class Discussion. Class discussion respect students' various idea and support students use new idea to solve complicated problems. When the class discussion located on the central position, students could feel fully that they are master in class and they have right and freedom. Students become study's master, and lead themself study. Teachers play the role of leader and pusher[6]. They control the time schedule, maintain the discussion order and the discussion direction.

The discussion section is divided into groups and then the whole class communicates and discusses. This way guarantees every students could take part in the class actively. Students should complete discussion paper before the class. Teacher would encourage students to explore the various ideas from the given topic. The students would be divided to groups in random. Every group has about four students. Before the discussion, there is one student has the freedom of speech, the other students must listen carefully the topic the student said. Students could show their idea in the observation and talk. By each questioned and personal defense, students could continuously inspect and correct their topic. Finally, apply the function of random selection, pick a random member of several groups, let students share their essence idea to the whole class.

Course Assessment. The change of teaching model will inevitably bring about the change of learning model, so the assessment model require the corresponding adjustment. It reflects the process evaluation to increase regular assessment appropriately and spread the study over the whole term. The curriculum teaching evaluation adopt the way of the combination of teacher evaluation and peer evaluation, the combination of process evaluation and final evaluation, the combination of classroom evaluation and after-class evaluation, and the combination of theoretical evaluation and practice evaluation to estimate the students learning outcomes fully, objectively and 
comprehensively. The class of computer programming use conformity assessment to let the students with low requirements can pass the exam successfully. It also opens assessment to the students with high requirements to show excellent space. This model can better adapt to students' different learning needs.

\title{
Practical Analysis
}

Through the implementation of two semesters of courses, teachers and students generally recognize the online teaching and classroom teaching integration model. Students have more freedom to choose their own learning goals, learning content, learning methods and learning materials. To a large extent, this has stimulated students' willingness to learn, and they are willing to take the initiative to take the responsibility of learning, and enter the study quickly and enthusiastically, so as to improve the learning effect and academic performance. Teachers are given more flexibility and enough time to expand, supervise and help students deepen their learning and application. The analysis of learners' learning data on the online platform provides technical support for students' personalized learning and helps teachers to carry out differentiated teaching at a deeper level.

Fig. 2 Students' satisfaction feedback on video resources on the online platform. It can be seen that most students are satisfied with video provided by extracurricular self-study, and of course, we also could see the students' demand for video with higher quality and more distinctive features.

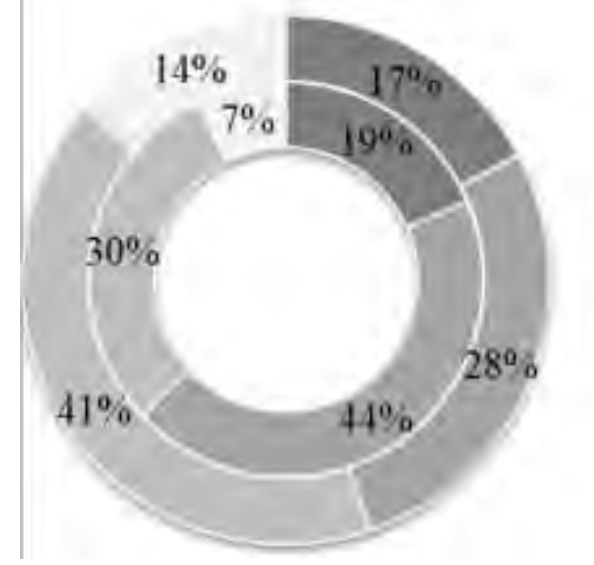

= Very good, fully meet the learning needs

wood, but needs to be improved

- Just so so,,be able to learn smoothly

Not too bad, a little help

Figure 2. The survey feedback about two semesters of teaching video use

Fig. 3 the test feedback about online platform operation. From it, we could see that the most of students need spend some energy completing homework.

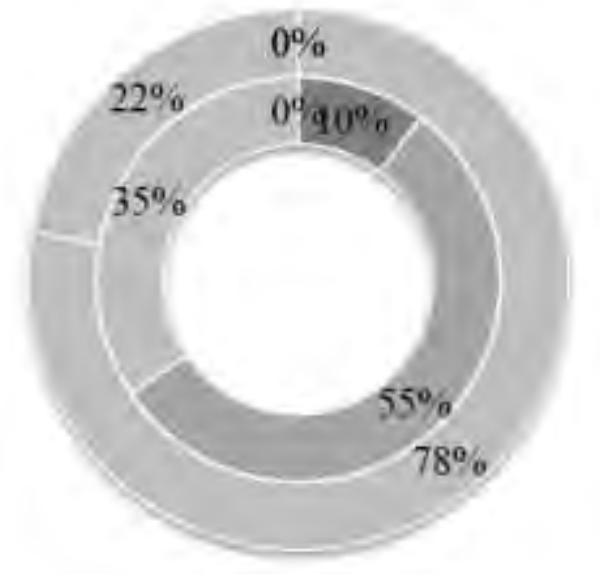

\author{
EIt's too bard, can not do it \\ int's a little difficult, I need to think about it a little. \\ It's not hard., I can do it
}

Not done

Figure 3. The test feedback about online platform operation

\section{Summary}

Carry out the reform of the blended learning model based on online platform and physical 
classroom, combined with the advantage of internet to study, could help the traditional class plays the traditional role better. Analyse the study process data could help teacher find the teaching phenomenon, master the teaching law, offer theoretical basis to adjust teaching strategies, so as to make teachers guide students more scientific and offer learning extension and supervision to the students. In the meanwhile, with the new technology push, students could change from learning knowledge to developing learning ability which is an indispensable ability in the society.

\section{Acknowledgements}

Fund program: 2017 university-level teaching research project of Wuhan Polytechnic University: The teaching reform of the online learning and classroom teaching based on PAD class (XM2017007).

\section{Reference}

[1] David Weinberger: Too Big to Know( Basic Books, 2014), p. 11.

[2] Salman Khan:The One World Schoolhouse: Education Reimagined(Twelve; Reprint , 2013)

[3] Michael B. Horn, Heather Staker:Blended: Using Disruptive Innovation to Improve Schools(Published by Jossey-Bass, 2014)

[4] Wuhan Polytechnic University online education service platform. http://whpu. fy. chaoxing. com

[5] Malcolm S. Knowles, Elwood F. Holton and Richard A. Swanson:The Adult Learner: The definitive classic in adult education and human resource development (Routledge; 8th New edition, 2015)

[6] Marcia C. Linn, Bat-Sheva Eylon:Science Learning and Instruction: Taking Advantage of Technology to Promote Knowledge Integration(Routledge Member of the Taylor and Francis Group, 2011)

[7] Bob Montgomery, Kurt Larsen and Gina Hale: Deeper Learning and e-learning(August 5, 2013). https://www. hewlett. org/library/deeper-learning-and-e-learning

[8] Clayton M. Christensen, Michael B. Horn and Heather Staker: Is K-12 Blended Learning Disruptive? ( MAY 2013)

https://www. org/wp-content/uploads/2013/05/Is-K-12-Blended-Learning-Disruptive. pdf

christenseninstitute.

[9] Kam Knight:Mind Mapping: Improve Memory, Concentration, Communication, Organization, Creativity, and Time Management (CreateSpace Independent Publishing Platform, 2012)

[10] Angela DeBarger: Connecting deeper learning with open educational resources (January 11, 2018)

https://www.

hewlett.

org/qa-angela-debarger-connecting-deeper-learning-open-educational-resources 